\title{
PERSEPSI DAN SIKAP MAHASISWA STIKES BALI TENTANG YOGA
}

\author{
Komang Ayu Purnama Dewi, Gusti Ayu Dwina Mastryagung, Ni Made Nurtini \\ Sekolah Tinggi Kesehatan Bali, Jalan Tukad Balian No 180 Renon Denpasar \\ Email: ayupurnama.stikesbali@gmail.com
}

\begin{abstract}
ABSTRAK
Senam yoga mulai dikenal tahun 90 -an di Indonesia. Perkembangan yoga di Indonesia terjadi ketika krisis ekonomi, yang berdampak bagi masyarakat seperti stres. Mereka yang mengalami stress mulai menyadari bahwa pengobatan medis tidak cukup ampuh mengobati penyakit yang sumbernya dari psikis atau mental. Mereka mulai berpaling pada upaya penyembuhan alami, diantaranya beryoga. Terbuka pada perkembangan gaya hidup, turut menjadi amunisi ampuh bagi ledakan yoga di kota-kota besar Indonesia. Seiring dengan pesatnya perkembangan yoga di dekade ini, ternyata masih banyak kesalahpahaman terhadap yoga. Umumnya kesalahpahaman ini muncul karena kurangnya informasi tentang yoga, khususnya bagi mahasiswa yang baru mulai tertarik. Tujuan Penelitian adalah untuk mengetahui persepsi dan sikap mahasiswa Stikes Bali tentang yoga. Metode pada penelitian adalah adalah deskriptif kuantitatif dengan pendekatan cross sectional, dengan sampel adalah seluruh mahasiswa STIKES Bali yang ada di kampus pada saat penelitian, yang diambil dengan teknik total populasi. Waktu penelitian adalah tanggal 1 sampai 28 Desember 2016. Sebagian besar mahasiswa Stikes Bali yaitu 278 orang $(55,6 \%)$ memiliki persepsi negatif yoga. Sebagian besar mahasiswa Stikes Bali yaitu 301 orang $(60,2 \%)$ memiliki sikap negative tentang yoga. Untuk selanjutnya perlu penelitian untuk mencari hubungan antar variable dengan jumlah responden yang lebih banyak. Kepada mahasiswa untuk lebih banyak mencari informasi tentang yoga agar tidak terjadi kesalahpahaman tentang yoga.
\end{abstract}

Kata kunci: persepsi, sikap, yoga

\begin{abstract}
Introduction: Yoga gymnastics has began on the 90's in Indonesia. The yoga 's was develop in Indonesia occurs when the economic crisis, which affects the strees of community. Those who has stress experience begin to realize that medical care is not enough to treat the psychic illness or mental sources. Yoga's lifestyle was contributing as power and high development, in the big cities of Indonesia. Along with the rapid increase in this decade, there are still many of misconceptions about yoga. Generally this misconception arises because of lack of information about yoga, especially for those who are just getting interested. Research Objective is to know about yoga perceptions and attitude Stikes Bali students. The research method was descriptive quantitative by cross sectional approach, with the total population technique sample of STIKES Bali students. The time of the study is from 1 to 28 December 2016. Most of the Stikes Bali students 278 (55.6\%) had negative perceptions of yoga and 301 students (60.2\%) have negative attitude about yoga. Hope the next researcher to continue this research to find the relationship between variables with the number of respondents. To the students to find more information about yoga in order to avoid misunderstandings about yoga.
\end{abstract}

Keywords: perception, attitude, yoga

\section{PENDAHULUAN}

Yoga terbentuk sejak abad 3000 SM dan berasal dari kebudayaan India kuno. Yoga atau dalam bahasa Sansekerta dikenal dengan sebutan Yuj berarti menghubungkan atau mempersatukan, yaitu penyatuan antara manusia dengan Tuhannya. Intinya, dengan yoga seseorang bisa mengenal dirinya lebih baik, sekaligus lebih mendekatkan diri pada Tuhannya. Yoga adalah kegiatan yang melibatkan pikiran dan tubuh dan digunakan untuk mencapai peningkatan kesehatan dan relaksasi (Devi.A, 2002).
Yoga menjadi salah satu pilihan alternatif olahraga harian dan dapat juga menjadi gaya hidup yang menyehatkan disamping joging atau treatmeal. Kini orang-orang semakin tertarik pada senam yoga daripada latihan kebugaran lain, seperti aerobik, BL, pilates dan lain sebagainya. Senam yoga telah dipraktikkan sejak 4000 tahun yang lalu. Orang-orang Barat sudah mulai mengenal latihan ini sejak 30 tahun terakhir. Mereka mulai merasakan manfaat besar dari berlatih yoga, yakni mencapai fleksibilitas dan mengurangi stres. Saat ini, ada jutaan orang Amerika yang sudah menuai manfaat yoga. Itu sebabnya perkembangan yoga di 
Amerika tak bisa disebut sebagai tren semata. Gairah orang Amerika untuk beryoga sudah lebih dari sekedar kebutuhan untuk berlatih atau kesehatan fisik, tapi sudah menjadi bagian dari gaya hidup (Somvir, 2009).

Di Indonesia, senam yoga mulai dikenal tahun 90-an. Perkembangan yoga di Indonesia, khususnya Jakarta, dimulai ketika terjadi krisis ekonomi vang terjadi pada pertengahan tahun 90 -an, membuat banyak dampak dalam masyarakat, di antaranya stres. Mereka yang dilanda stres itu mulai menyadari bahwa pengobatan medis tak cukup ampuh mengobati penyakit yang sumbernya dari psikis atau mental. Mereka lantas mulai berpaling pada upaya penyembuhan alami, diantaranya beryoga. Hal lain yang menjadi vitamin perkembangan yoga adalah kebiasaan yang dibawa anak-anak Indonesia yang pernah belajar di luar negeri, khususnya Amerika Serikat. Anak-anak yang berasal dari keluarga kelompok paling atas sampai menengah-atas, yang ketika sekolah atau tinggal di Amerika sudah mengenal dan berlatih yoga, kemudian merasakan manfaatnya. Mereka kemudian meneruskan kebiasaan tersebut sekembalinya ke tanah air. Selain mereka, banyak juga orang Indonesia, yang walaupun tidak ke Amerika, tapi cukup terbuka pada perkembangan gaya hidup, turut menjadi amunisi ampuh bagi ledakan yoga di kota-kota besar Indonesia (Sumantra dan Dindia, 2015).

Dalam delapan tahun terakhir ini, perkembangan tempat untuk berlatih yoga atau yoga center di Indonesia, Jakarta khususnya, meningkat dengan pesat. Animo dan kegandrungan masyarakat Jakarta yang berpenduduk sembilan juta lebih ini untuk beryoga menunjukkan grafik yang meningkat. Pemberitaan dan publikasi yoga di media, baik cetak maupun elektronik, seperti terus mengalir tiada henti. Sejak tahun 2008, Bali Spirit Festival menjadi pionir dalam menyelenggarakan festival yoga di Indonesia berskala internasional. Sementara di tahun 2010, Namaste Festival juga mulai diadakan di Jakarta. Meskipun memiliki kemasan berbeda, namun keduanya memiliki benang merah yang sama, yakni mempopulerkan yoga sebagai sebuah gaya hidup bagi masyarakat Indonesia (Sumantra dan Dindia, 2015).

Sutarya dalam Metro Bali (2016), mengatakan perpaduan antara alam, budaya dan etnis merupakan pendukung utama untuk pengembangan pariwisata yoga di Bali. Budaya dan etnis Bali sangat mendukung orisinalitas yoga yang memang berasal dari masyarakat Hindu.

Kegiatan yoga juga sudah dilakukan di masyarakat umum maupun instansi pendidikan, seperti: yoga masal serangkaian kegiatan Sanur Village Festival (SVF) ini dimulai sekitar pukul
06.30 hingga 08.15 Wita. Sejumlah wisatawan asing, orang tua bahkan anak-anak sekolah mengikiti dengan tekun gerakan yoga kesehatan tersebut (Pemerintah Kota Denpasar, 2008). Kegiatan yoga masal juga dilakukan atas kerjasama antara Fakultas Ilmu Agama Dan Kebudayaan dengan PHDI Bali. Kerjasama kegiatan ini dalam rangka memeriahkan hari ulang tahun Fakultas Ilmu Agama dan Kebudayaan dan program Pascasarjana UNHI, yang dihadiri oleh dosen, mahasiswa, siswa SD sampai SMA se-kota, penggiat yoga di Bali, perwakilan PHRI, Kaum lansia dan perwakilan kopertis wilayah VII Bali Nusra (Suluh Bali, 2015). Rika dalam Tribun Bali (2014), mengatakan sekolah di Denpasar akan segera merealisasikan ekstrakulikuler yoga. Bahkan staf dan pegawai di SMAN 4 Denpasar sudah rutin menngadakan latihan yoga, namun penerapan ke siswa masih menunggu penyelesaian penyususnan silabus. STIKES Bali merupakan salah satu instansi kesehatan di Bali juga telah menambahkan yoga pada kurikulumnya dan memberikan praktek yoga sebagai salah satu terapi komplementer. Selain dalam kurikulum, yoga juga menjadi salah satu kegiatan yang telah dilaksanakan oleh BEM (Badan Eksekutif Mahasiswa).

Seiring dengan pesatnya perkembangan yoga di dekade ini, ternyata masih banyak yang salah paham terhadap yoga. Umumnya kesalahpahaman ini muncul karena kurangnya informasi tentang yoga, khususnya bagi mereka yang baru mulai tertarik. Berikut beberapa kesalahpahaman tentang yoga : yoga hanyalah untuk mereka yang muda, kuat dan atletis, hanya bagi mereka yang berbadan sehat dan yoga adalah praktek agama. Berdasarkan uraian di atas peneliti tertarik meneliti tentang persepsi dan sikap mahasiswa STIKES Bali tentang yoga.

\section{BAHAN DAN METODE \\ Desain Penelitian}

Penelitian ini merupakan penelitian deskriptif kuantitatif dengan rancangan cross sectional, untuk mengetahui Persepsi dan Sikap Mahasiswa Stikes Bali tentang Yoga

\section{Populasi dan Sampel}

Populasi pada penelitian ini adalah adalah seluruh mahasiswa STIKES Bali yang berada di kampus pada saat penelitian yaitu Prodi DIII Keperawatan tingkat 1 dan 3, Prodi S1 Keperawatan tingkat 1 dan prodi DIII Kebidanan tingkat 1. Cara Pengambilan sampel dalam penelitian ini adalah dengan non probability sampling dengan total populasi

\section{Instrumen Pe nelitian}

Tehnik pengumpulan data dalam penelitian ini adalah mempergunakan kuesioner yaitu 
kuesioner tentang Persepsi dan Sikap Mahasiswa Stikes Bali tentang Yoga

\section{Pengumpulan dan Analisa Data}

Calon responden diberikan penjelasan tentang maksud dan tujuan dilakukannya penelitian. Selanjutnya peneliti menyerahkan surat permohonan menjadi responden. Calon responden baru bisa mengisi kuesioner setelah menandatangani surat persetujuan menjadi responden (Informed concent). Analisis data yang digunakan dalam penelitian ini adalah analisis univariat. Dalam analisis ini, variabel disusun secara deskriptif untuk menggambarkan karakteristik masing-masing melalui tabel frekuens

\section{HASIL DAN PEMBAHASAN}

Karakte ristik Mahasiswa Stikes Bali

Tabel 1. Distribusi Frekuensi Persepsi Mahasiswa Stikes Bali tentang Yoga

\begin{tabular}{lcc}
\hline \multicolumn{1}{c}{ Karakteristik } & f & \% \\
\hline Prodi & & \\
S1 Kep & 247 & $49,4 \%$ \\
D3 Kep & 176 & $35,2 \%$ \\
D3 Keb & 77 & $15,4 \%$ \\
Jenis Kelamin & & \\
Perempuan & 348 & $69,6 \%$ \\
Laki-laki & 152 & $30,4 \%$ \\
\hline
\end{tabular}

Berdasarkan tabel 1 dapat dilihat bahwa sebagian besar mahsiswa berasal dari prodi S1 Keperawatan dan sebagian besar berjenis kelamin perempuan.

Persepsi Mahasiswa Stikes Bali tentang Yoga

Tabel 2. Distribusi Frekuensi Persepsi Mahasiswa Stikes Bali tentang Yoga

\begin{tabular}{lcc}
\hline \multicolumn{1}{c}{ Perse psi } & f & \% \\
\hline Positif & 222 & $44,4 \%$ \\
Negatif & 278 & $55,6 \%$ \\
\hline Total & 500 & $100 \%$ \\
\hline
\end{tabular}

Berdasarkan tabel 2 dapat dilihat bahwa sebagian besar mahasiswa Stikes Bali yaitu 278 orang (55,6\%) memiliki persepsi negatif yoga.

Sikap Mahas is wa Stikes Bali tentang Yoga

Tabel 3 Distribusi Frekuensi Sikap Mahasiswa Stikes Bali tentang Yoga

\begin{tabular}{lcc}
\hline \multicolumn{1}{c}{ Sikap } & f & \% \\
\hline Positif & 199 & $39,8 \%$ \\
Negatif & 301 & $60,2 \%$ \\
\hline Total & 500 & $100 \%$ \\
\hline
\end{tabular}

Berdasarkan tabel 3 dapat dilihat bahwa sebagian besar mahasiswa Stikes Bali yaitu 301 orang $(60,2 \%)$ memiliki sikap negatif tentang yoga.

Yoga adalah kegiatan yang melibatkan pikiran dan tubuh dan digunakan untuk mencapai peningkatan kesehatan dan relaksasi (Devi.A, 2002). Seiring dengan pesatnya perkembangan yoga di dekade ini, ternyata masih banyak yang salah paham terhadap yoga. Umumnya kesalahpahaman ini muncul karena kurangnya informasi tentang yoga, khususnya bagi mereka yang baru mulai tertarik. Berikut hasil penelitian persepsi dan sikap mahasiswa Stikes Bali tentang yoga:

Sebagian besar mahasiswa Stikes Bali memiliki persepsi negatif tentang yoga. Hal ini didukung dari jawaban pernyataan responden dalam kuesioner yaitu masih ada yang berpersepsi jika yoga hanyalah untuk mereka yang muda, kuat dan atletis sebanyak 65 orang (13\%). Menurut Harsawardana (2011), bila melihat foto yang menggambarkan pose yoga yang lentur, dapat memperoleh kesan bahwa yoga hanyalah untuk mereka yang muda, kuat dan atletis. Sebenarnya, bila merasa bahwa seseorang tidak mampu melakukan yoga, maka yoga justru akan sangat membantu. Jadi orang tanpa pengalaman yoga justru paling cepat memperoleh kemajuan/manfaat untuk kondisi kesehatan, dibandingkan dengan mereka yang sudah sering berlatih. Berlatih yoga tidak hanya menjadi kegiatan yang menyenangkan untuk kalangan dewasa dan anak muda semata. Yoga bisa dilakukan oleh siapa saja. Semua orang dapat mengikuti latihan yoga sesuai dengan kapasitas masing-masing. Yoga tidak terhalang batas usia, semua orang dapat berlatih yoga. Begitu pula dengan status sosial, profesi maupun 
kedudukan seseorang. Bahkan, ada juga prenatal dan postnatal yoga untuk ibu hamil (Anonim, 2017)

93 orang $(18,6 \%)$ setuju bahwa yoga hanya untuk membentuk tubuh. Menurut Worby (2007) selain untuk melenturkan dan memperbaiki postur tubuh, yoga juga bermanfaat untuk menjaga tetap bugar, memperbaiki sirkulasi darah dan kelenjar getah bening di selruh tubuh, menghilangkan penyakit kronis dan menghilangkan stres, membantu menjadikan rileks, menjaga kepadatan tulang, menjaga keseimbangan emosi serta meningkatkan kehidupan seksual. Banyak penelitian sudah dilakukan baik di India maupun Barat bahwa yoga dapat digunakan untuk terapi kesehatan, baik itu kesehatan fisik, mental maupun emosional. Walaupun yoga bukanlah obat, namun kombinasi antara pengobatan medis dengan latihan yoga dapat membantu menyembuhkan berbagai macam penyakit dengan lebih cepat dan efektif. Hal ini karena yoga menggunakan pendekatan holistik terhadap diri manusia sehingga dapat diaplikasikan untuk setiap orang (Harsawardana, 2011).

Mengenai sikap mahasiswa Stikes Bali tentang yoga, didapatkan hasil sebagian besar mahasiswa Stikes Bali memiliki sikap negatif. Hal ini didukung dari jawaban pernyataan responden dalam kuesioner yaitu 242 orang $(48,4 \%)$ mahasiswa setuju bahwa berlatih yoga berarti mempraktekkan salah satu ajaran agama dan 220 orang (44\%) mahasiswa yang setuju jika rutin berlatih yoga, orang akan memandang sebagai seseorang yang religius. Yoga memang berasal dari India, namun bukan praktik agama Hindu yang kebetulan juga berasal dari India. Betul bahwa ada sisi spiritual dalam yoga, namun tidak harus terikat terhadap suatu agama tertentu untuk mempraktikkan yoga. Bisa melakukan pendekatan "ambil yang diperlukan dan lupakan yang lainnya" terhadap yoga. Bila hanya menginginkan kesehatan fisik, silakan latihan asanas sebanyak-banyaknya. Tidak ada paksaan apapun dalam berlatih yoga karena memanghanya seseorang akan merasakan manfaat yoga secara keseluruhan (Harsawardana, 2011). Praktik-pratik yoga di Indonesia pada umumnya netral. Tidak mengajarkan ritual agama. Bahkan, saat ini yoga cenderung menjadi gaya hidup yang tentu saja makin jelas terpisah dari ritual agama. Di Indonesia, yoga pada umumnya memang dilakukan untuk tujuan kesehatan fisik dan mental (Sindhu.P, 2017).

\section{SIMPULAN DAN SARAN SIMPULAN}

Sebagian besar mahasiswa Stikes Bali yaitu 278 orang $(55,6 \%)$ memiliki persepsi negatif tentang yoga.

Sebagian besar mahasiswa Stikes Bali yaitu 301 orang $(60,2 \%)$ memiliki sikap negatif tentang yoga.

\section{SARAN}

Peneliti selanjutnya agar melanjutkan penelitian untuk mencari hubungan antar variable persepsi dengan sikap

Kepada mahasiswa untuk lebih banyak mencari informasi tentang yoga agar tidak terjadi kesalahpahaman tentang yoga

Kepada institusi dalam mengajarkan yoga sebaiknya memberikan informasi yang lengkap tentang yoga serta evaluasi kurikulum tentang yoga

\section{UCAPAN TERIMAKASIH}

Terimaksih penulis ucapkan kepada STIKES Bali yang telah memberikan kesempatan untuk melakukan dan sekaligus mendanai penelitian ini, kepada seluruh mahasiswa sebagai responden dan semua pihak yang ikut membantu kelancaran proses penelitian ini. Serta terimaksih kepada tim redaksi jurnal kesehatan terpadu Dyana Pura atas kesempatannya untuk mempublikasikan hasil penelitian ini.

\section{DAFTAR PUSTAKA}

Devi.A. (2002). Yoga Untuk Semua Panduan Berlatih Yoga Yang Lengkap dan Aman. PT Granedia Pustaka Utama

Harsawardana. (2011). Konsep Terapi Yoga. Retrieved from: https://susanharsawardana.wordpress.com/201 $1 / 10 /$

Sindhu.P. (2017). Pilih Yoga Sesuai Hati. Bandung: Yoga Leaf

Somvir. (2009). Yoga dan Ayurveda Selalu Sehat dan Awet. Bali-Indian Foundation

Sumantra Md., Dindia D. (2015). Modul Pelatihan Teacher Traing Markadeya Yoga Healing. Markadeya Yoga Indonesia

Worby. (2007). Memahami Segala Tentang Yoga. Tangerang:

Karisma 